\title{
Letramento e ludicidade: a construção de uma identidade extensionista
}

Janaina Assis Rufino ${ }^{1}$

jana.assis@hotmail.com

Mauro Rocha Baptista ${ }^{2}$

m-baptista@uol.com.br

Elisabeth Gonçalves Souza ${ }^{3}$

elisabeth.souza@uemg.br

\section{Resumo}

Este artigo objetiva discutir as perspectivas teórico-práticas que movimentam o Laboratório Teórico-Prático do Brincar (LABRINC), buscando uma reflexão que nos permita refletir sobre a construção de um programa de extensão para as ações que desenvolvemos no Núcleo de Pesquisa Educação, Subjetividade e Sociedade. Acreditamos que a sistematização das ações de extensão em programas é um mecanismo bastante eficaz das universidades para o cumprimento das diretrizes de impacto, interação social dialógica, construção de parcerias, interdisciplinaridade e integração ensino-pesquisa-extensão, como previsto também nas decisões tomadas no Forproex (BRASIL, 2007).

Palavras-chave: Programa de extensão, letramento, ludicidade

\section{Considerações iniciais}

Nossa proposta neste artigo é discutir as perspectivas teórico-práticas que movimentam o Laboratório Teórico-Prático do Brincar (LABRINC), buscando uma reflexão que nos permita alcançar uma sistematização

1 Doutora em Estudos Linguísticos pela UFMG. Universidade do Estado de Minas Gerais/Barbacena. 2 Doutor em Ciência da Religião (UFJF). Universidade do Estado de Minas Gerais/Barbacena.

3 Doutora em Linguística do Texto e do Discurso. Universidade do Estado de Minas Gerais/Barbacena. 
de nossas ações e nos autorize propor uma nucleação dessas ações de extensão, ou seja, que nos permita refletir sobre a construção de um programa de extensão para as ações que desenvolvemos no Núcleo de Pesquisa Educação, Subjetividade e Sociedade (NPESS).

Acreditamos que a sistematização das ações de extensão em programas é um mecanismo bastante eficaz das universidades para o cumprimento das diretrizes de impacto, interação social dialógica, construção de parcerias, interdisciplinaridade e integração ensinopesquisa-extensão, como previsto também nas decisões tomadas no Plano Nacional de Extensão Forproex ${ }^{4}$ (BRASIL, 2007).

Buscamos em nosso Núcleo de Pesquisa uma proposta de extensão que transcenda a conceitos vulgares de extensão como assistencialismo ou mera prestação de serviço. Pretendemos trabalhar com uma concepção de extensão tomada como "processo educativo, cultural e científico que articula o ensino e a pesquisa de forma indissociável e viabiliza a relação transformadora entre a Universidade e a Sociedade" (BRASIL, 2007, p. 16). Por meio da extensão, a universidade, em nosso ponto de vista, é o espaço capaz de oportunizar a divulgação à comunidade dos conhecimentos de que é detentora. A extensão universitária, para o NPESS, é a forma de socializar e democratizar o saber científico, de modo a este não se traduzir em privilégio apenas da minoria da população, mas difundido também à comunidade não acadêmica, de acordo com os próprios interesses dessa mesma comunidade.

Para sistematizar de nossas ações de extensão, é necessário que façamos a priori uma reflexão sobre a nossa própria trajetória como Núcleo de Pesquisa desde as discussões dos conceitos que estruturaram a aproximação dos pesquisadores que compõem esse grupo à realização, concretização e aprovação em agências de fomento de projetos que acabaram por se compor em facetas de nós mesmos, que vamos tentando compreender e ressignificar a cada dia em nossa prática.

A trajetória do Núcleo de Pesquisa Educação, Subjetividade e Sociedade tem início em 2006, com a possibilidade de diálogo entre dois grupos de pesquisas do campus Barbacena, estruturados a partir das

4 Fórum de Pró-Reitores de Extensão (2007). 
pesquisas individuais desenvolvidas por seus coordenadores: Leitura e escrita: reflexões, coordenado pela professora Janaína de Assis Rufino e Ética e religião, coordenado pelo professor Mauro Rocha Baptista. O primeiro grupo objetivava buscar uma conceituação metodológica contemporânea de leitura à luz de três concepções (pedagógica, linguístico-textual e discursiva) para fomentar um repensar sobre a prática escolar dos fenômenos leitura e escrita. O segundo grupo debatia epistemologicamente com várias disciplinas para uma releitura da identidade humana no processo de educação do sujeito a partir de dois temas inextrincáveis: a religião e a ética.

A possibilidade de uma proposta de universidade para além de ser considerada uma instituição transdiciplinar de formação dos quadros profissionais de nível superior, de pesquisa, de ensino, de extensão e de domínio e cultivo do saber humano estabeleceu entre os dois grupos de pesquisas e outros pesquisadores do Campus Barbacena (como os professores Cláudio José Guilarduci e Fuad Kyrillos Neto) uma possibilidade efetiva de aproximação. A unificação dos grupos, aliada à chegada desses pesquisadores, acabou por consolidar um espaço de discussão comum, capaz de agregar, em um diálogo interdisciplinar, os diversos estudos realizados pelo corpo docente que na época se dedicava principalmente às suas pesquisas pessoais relativas à suas qualificações.

Inicialmente, os diálogos se estabeleceram num movimento dialético próprio da abordagem interdisciplinar assumida no exercício de aproximação entre produções e pesquisas particulares do corpo docente e a busca de novos pressupostos conceituais para futuras produções coletivas do grupo. Dentro de uma proposta de trabalho com metodologia dialética, consideramos, na época, relevante operarmos com um conceito de educação que transcendesse o experimentalismo, o didatismo e as noções de etapas desenvolvimentistas.

Para tanto, e de acordo com a formação desse grupo, foram adotadas as noções de "discurso", na condição de construção de subjetividades e de "conflito", inerente às relações sociais, para a possibilidade de extrair novos pressupostos para o trabalho em educação. Ponto comum aos integrantes do Núcleo foi a noção de que o ponto de partida da educação é 
a educabilidade situada na dialética do ser e do não ser, conceito adotado no projeto ${ }^{5}$ que veio a estruturar o Núcleo.

À busca da concretização de espaço, conjunto de discussão e produção, ainda em 2006, esse grupo de professores se reúne sob a coordenação do professor Cláudio Guilarduci para a elaboração e submissão do projeto de Otimização do Laborátorio de Pesquisa Téorico-Prático do Brincar (LABRINC). A composição do laboratório se manteve atenta aos três primeiros princípios básicos da extensão propostos pelo Forproex (BRASIL, 2007):

A ciência, a arte e a tecnologia devem alicerçarse nas prioridades do local, da região, do país; a universidade não pode se imaginar proprietária de um saber pronto e acabado, que vai ser oferecido à sociedade, mas, ao contrário, exatamente porque participa dessa sociedade a instituição deve estar sensível a seus problemas e apelos, quer através dos grupos sociais com os quais interage, quer através das questões que surgem de suas atividades próprias de ensino, pesquisa e extensão; a universidade deve participar em todos os movimentos sociais, priorizando ações que visem a superação das atuais condições de desigualdade e exclusão existentes no Brasil (p. 4).

O objetivo do LABRINC é a formação, por meio de pesquisas, de um quadro de pesquisadores em "campo lúdico" para atender às necessidades da construção de um conhecimento teórico-prático que possa refletir no processo de ensino-aprendizagem no espaço regular de nossas atividades disciplinares e, simultaneamente, atender à necessidade de construção de um espaço concreto possível e adequado para a produção de tais pesquisas. O Laboratório foi organizado a partir de três princípios metodológicos norteadores de todo e qualquer processo de pesquisa. O primeiro princípio constitui o LABRINC em um espaço de "trabalho interdisciplinar" aberto a pesquisadores com diferentes áreas de formação ou experiências. Acreditamos que, somente através de visões e perspectivas diferenciadas, a pesquisa e o ensino, no entendimento do

5 Projeto de implementação do Núcleo de Pesquisa Educação, Subjetividade e Sociedade, financiado pela FAPEMIG. 
lúdico, da brincadeira, do brinquedo, do jogar e, consequentemente, da arte, possibilitarão um estudo mais rico e aprofundado sobre o lúdico.

O segundo princípio, a profunda "relação com a comunidade", pois a especificidade do campo de estudo - o lúdico -, requer a criação de vínculos num espaço social mais amplo com o envolvimento de entidades e pessoas que desenvolvam ou têm interesse em trabalhar, sistematicamente, com atividades lúdicas.

O último princípio a nortear as atividades do laboratório é a "relação entre teoria e prática no campo da investigação lúdica". Essa prática é entendida como mais um momento de laboratório rigorosamente necessário para o pleno desenvolvimento dos estudos em campo lúdico.

A estrutura do LABRINC pode ser definida conforme a descrição da matéria de divulgação acadêmica na revista Minas faz ciência (2008):

Construído com financiamento da FAPEMIG, o laboratório é uma sala de aula ambientada com material lúdico. São jogos pedagógicos, de construir, matemáticos, lógicos, quebra-cabeças, teatros de fantoche, CDs e DVDs, todos direcionados ao público infantil. O espaço também inclui material para pesquisa, como livros, artigos e computadores (MINAS FAZ CIÊNCIA, 2008, p. 46-47).

O LABRINC, na verdade, é um espaço para a aquisição de um arcabouço metodológico e técnico centrado na reflexão sobre as brincadeiras e os jogos, contrapondo à já antiga ideia de que a "parte" teórica é a inicial e a parte "prática" como a etapa de mera experimentação que só pode ocorrer após um entendimento da literatura. Assim sendo, nossa proposta para trabalhar o lúdico na educação passa por um conceito de educação que tem como pilares os procedimentos do discurso e do conflito, conceitos esses que desde nossa união fundamentaram nossas discussões.

O LABRINC, como espaço convergente de atividades de pesquisa e extensão realizadas pelos professores do núcleo, possibilita um trabalho interdisciplinar acerca da educação, doando a seus integrantes uma metodologia própria calcada na discussão que o seu projeto de otimização proporciona quando reelabora o conceito de lúdico. 
Uma metodologia que pretenda alcançar o uso do lúdico, que propomos, na educação deve atentar antes de qualquer outra coisa para o fato de que a função transformadora que o lúdico possui não representa algo que lhe é externo, algo que lhe é agregado por um esforço didático-metodológico. Gadamer (1997), ao analisar o lúdico presente na obra de arte, diz:

A obra de arte tem, antes, o seu verdadeiro ser em se tornar uma experiência que irá transformar aquele que a experimenta. $\mathrm{O}$ "sujeito" da experiência da arte, o que fica e persevera, não é a subjetividade de quem a experimenta, mas a própria obra de arte. Encontra-se aí justamente o ponto em que o modo de ser do jogo se torna significante. Pois o jogo tem uma natureza própria, independente da consciência daqueles que jogam (p. 175-176).

O lúdico se apossa do sujeito que dele faz experiência tanto adquirindo independência dele quanto gerando dependência a ele. Assim, não é o jogo que se desvela sob a análise do jogador, mas o jogador que se desvela a si mesmo pelo jogo. O sujeito transformado pelo lúdico refaz a sua própria identidade. Logo, para não trair o próprio objeto a que nos propomos analisar, o método assumido deve ser cientificamente rigoroso, como compete ser uma atividade acadêmica, mas deve manter a maleabilidade intelectual, como carece ser a análise de um objeto capaz de, ao se transformar, transformar os sujeitos que dele experimentam.

É Agamben (2008) quem apresenta tal metodologia ao questionar a "via certa" perseguida pela experiência científica. Segundo ele, ante as aporias do mundo, não é possível arcar com esse rigorismo que ultrapassa a necessidade de qualquer ação científica. Não é mais cabível, ao menos não após as considerações contra-dogmáticas sistematizadas no pensamento moderno por Immanuel Kant, acreditar na constituição de uma "via certa", ou de um "caminho reto e seguro para a salvação", conforme o desejo da cristandade medieval. Contra esse método que se limita aos objetivos propostos para realizar um caminho reto, Agamben (2008) apresenta a postura maleável do cavaleiro Percival em sua busca (quête) do santo graal. Percival encontra o objeto de sua quête porque se deixa desviar para auxiliar aqueles que dele precisam. A quête permite 
que nos desvios do caminho reto proposto pelo método se obtenha uma maior compreensão do universo lúdico.

Enquanto a experiência científica é de fato a construção de uma via certa (de uma méthodos, ou seja, de um caminho) para o conhecimento, a quête é, em vez disso, o reconhecimento de que a ausência de via (a aporia) é a única experiência possível para o homem. Mas, pelo mesmo motivo, a quête é também o contrário da aventura, que, na idade moderna, apresenta-se como o último refúgio da experiência e que esse caminho passe pelo extraordinário e pelo exótico (contraposto ao familiar e ao comum); enquanto que, no universo da quête, o exótico e o extraordinário são somente a marca da aporia essencial de toda experiência. (AGAMBEN, 2008).

Utilizando o conceito de quête, tentativa aporética de unir aquilo que se conhece pela ciência e o que é sentido pela experiência, Agamben (2008) abre a possibilidade para a aplicação de um método que não se submete à busca de um caminho definitivo, mas que, compreendendo a limitação dos caminhos familiares e exóticos, propõe-se a experimentar o que a ciência considera comum como algo extraordinário.

Por meio dessa quête, é possível "experienciar" o lúdico e alcançar o rigor necessário para a análise científica, reconhecendo que, diante dessa experiência aporética, não é o sujeito que funda as bases de seu conhecimento na simples adequação de seu conceito com a forma da coisa (conforme a fórmula tomista faz supor), mas é a multiplicidade do mundo quem obriga ao sujeito se lançar em uma busca pelo uno. O queéconhecido na pluralidade de formas a qual o intelecto se lança deve ser submetido à unicidade sensível da alma. Como essa unicidade essencial se prende ao sensível, o resultado redunda em uma constante aporia. Assumindo, pela via maleável da quête, a aporia como parte integrante da realidade analisada, podemos avaliar a estruturação do lúdico, não a partir de resultados meramente quantificáveis em um rigorismo científico tipicamente metodológico, mas a partir de sua capacidade uniforme de transformar os sujeitos. Qualquer análise menos maleável do lúdico perderia o seu essencial elemento de mutação interna e transformação externa.

O elemento essencial que pretendemos avaliar no lúdico não é "como" 
os sujeitos são transformados em contato com a sua estrutura, para essa análise bastaria uma sequência de falsificações pseudorrigorosas de dados estatísticos, mas é, exatamente, o seu poder de transformar, em sua pureza a-metódica que nos interessa. Se não se pode submeter o lúdico a uma série de regras didático-metodológica para que ele não perca esse elemento, sua análise não pode se submeter teoricamente àquilo que critica na prática. Contudo, a abertura maleável do método não significa falta de rigor. O rigor científico se apresenta na análise contundente que a equipe se propõe a fazer do objeto. Contundência que precisa ser coerente com a impossibilidade de se ater a meros rigorismos, tanto na experiência do lúdico quanto na sua análise. Se permitindo agir de forma maleável, a equipe reconhece o caminho a se seguir, mas reconhece também as aporias que esse caminho apresenta.

Ao assumir essa concepção complexa de ludicidade, começamos a perceber que outro conceito tão complexo como esse também nos acompanhava em nossas ações e reflexões. A presença de pesquisadores com formação nos estudos da linguagem e na educação com discussões a cerca do letramento e suas facetas nos possibilitou compreender de forma mais ampla uma possibilidade de o significado do lúdico que utilizamos se constituir como elemento fundamental de um "letramento" para o mundo.

Considerando o letramento uma prática que respeita a discussão crítica, partimos de Paulo Freire para desvencilhar essa prática da mera alfabetização bancária. Freire (1980) faz severas críticas a essa concepção através do que chama de educação bancária e a descreve como um ato de depositar, no qual os alunos são depositários e o professor aquele que deposita. (FREIRE, 1980). Para o autor, na concepção bancária da educação, o conhecimento é um dom concedido aos alunos por aqueles que o detém, no caso, os professores. Projetar uma ignorância absoluta sobre os outros é característica de uma ideologia de opressão. (FREIRE, 1980)

Paulo Freire considera esse tipo de prática como domesticadora, pois não desenvolve a consciência crítica dos educandos, apenas reforça a consciência ingênua, que facilita a manipulação da classe dominada. Para o autor, seria necessário a expansão da alfabetização, numa perspectiva 
política para que os analfabetos, em especial os adultos, pudessem se tornar sujeitos da própria história, modificando a realidade de seu contexto. $\mathrm{O}$ autor defende o processo de alfabetização como prática libertadora, como ação cultural para a libertação, que vê o educando como um sujeito cognoscente e que assume como objetivo desenvolver a consciência crítica dos oprimidos para que esses se percebam como classe para si. Freire (1980) afirma que alfabetização é um ato político e, portanto, não pode ser reduzida ao puro aprendizado mecânico de leitura e escrita. Ele acredita que a alfabetização deve ser parte do processo através do qual os homens, além de aprenderem a ler e a escrever, responsabilizam-se pela transformação social.

Evidenciamos que o conceito defendido por Freire e seus seguidores se aproxima do conceito de letramento que emergiu no Brasil na década de 1980, porém não há inscrição na obra freireana do conceito de letramento, mesmo porque o contexto cronológico das discussões freireanas são anteriores às do letramento no Brasil. Mesmo em suas obras lançadas posteriormente à década de 1980, não percebemos a utilização do termo. Naquela década, emergia o conceito de letramento que apontava para os usos sociais da leitura e da escrita em contraposição à simples decodificação dos símbolos, como propunha a educação tradicional e memorística. De acordo com Marinho (2007):

Até o final dos anos 1980, as palavras alfabetização e seus correlatos (alfabetizado, analfabeto, semianalfabeto, semi-analfabetizado, alfabetismo), leitura e escrita eram as principais palavras do nosso repertório para falar da relação das pessoas, da escola ou da sociedade escrita (MARINHO, 2007, p. 1).

A palavra alfabetização designava, então, todos os eventos relacionados com o ato de ler e escrever e as práticas inerentes a esses eventos. Num movimento não só brasileiro, mas mundial, como pode ser verificado por Soares (2004), a palavra letramento aportou no Brasil com uma carga comum aos neologismos: de novidade, de medo, de invenção e reinvenção. Soares (2004) afirma ter sido Kato quem primeiramente utilizou o termo letramento em uma obra lançada em 1986 intitulada No 
mundo da escrita, mas segundo a mesma autora, a primeira publicação que discutia o conceito foi de Tfouni (1988), em Letramento e alfabetização. A obra de Tfouni abriu a discussão a partir das definições de escrita, alfabetização e letramento.

Derivado do inglês literacy = "condição de ser letrado", a palavra letramento chegou carregada de controvérsias, dado o sentido de letrado expresso na tradução (pessoa erudita versada em letras), ser diferente do real sentido proposto com o novo (ligado à apropriação da escrita e de suas práticas sociais). Refere-se a tornar a "escrita própria, ou seja, é assumi-la como propriedade" (SOARES, 2004. p. 39).

As controvérsias e, de certa maneira, a reinvenção ou a recusa na aceitação do novo conceito, não foi privilégio apenas brasileiro. $\mathrm{Na}$ França, também aconteceu o chamado afrancesamento, devido a contextos próprios de cada país e à discussão com teorias já existentes. Marinho (2007) considera que

O termo aqui aportou como um dispositivo teórico para se compreender um fenômeno sócio-cultural, os modos e condições com que a sociedade brasileira lida com a escrita. Mas, como costuma acontecer com outros conceitos, o letramento vem entrando na sala de aula, nos livros didáticos destinados ao ensino da escrita. No embate sobre os métodos de alfabetização, somos pressionados a avaliar a influência do conceito de letramento sobre as ações do professor e o conteúdo da alfabetização na sala de aula e as concepções de letramento presente nos discursos e nas práticas da sala de aula (MARINHO, 2007, p. 3).

É preciso enfatizar que os estudos mais recentes apontam o letramento como sendo uma prática social, deixando para trás o conceito compreendido como codificação e decodificação de símbolos organizados em qualquer sistema que representa a linguagem oral. $\mathrm{O}$ modelo com base na decodificação foi muito discutido até a década de 70 . A partir dos estudos de Scribner e Cole (1981), baseados na perspectiva sociocultural, as práticas de letramento passaram a ser percebidas como um produto social vinculadas ao contexto histórico, político e ideológico em que se situam. (MACEDO, 2004) 
O chamado modelo autônomo (STREET, 1984), ligado à codificação e à decodificação, apresentava uma visão da escrita como objeto abstrato e neutro, descontextualizado, sendo a escrita um produto completo em si mesmo. De acordo com Kleiman (1995, p. 22), "nesse modelo a escrita não estaria presa ao contexto de sua produção para ser interpretada; o processo de interpretação estaria determinado pelo funcionamento lógico interno ao texto escrito". Para Rojo (2000):

$\mathrm{O}$ "modelo autônomo" define-se principalmente, por pressupor uma maneira única e universal de desenvolvimento do letramento (filo e ontogeneticamente), quase sempre associada a resultados e efeitos civilizatórios, de caráter individual (cognitivos) ou social (tecnológicos, de progresso e mobilidade social) (ROJO, 2000. p. 2).

O modelo de letramento que busca compreender as práticas de leitura e escrita, representando então um avanço em relação ao modelo anterior, é o modelo ideológico. (STREET, 1984) No modelo ideológico, as práticas de leitura são compreendidas como práticas contextualizadas, construídas em espaços específicos. Tal modelo pressupõe a existência de vários tipos de letramento, várias práticas ligadas à cultura e às estruturas de poder da sociedade. Ressaltamos que o modelo ideológico não é a negação do modelo autônomo, o que pode ser verificado em Kleiman (1995).

O modelo ideológico, portanto, não deve ser entendido como uma negação de resultados específicos dos estudos realizados na concepção autônoma do letramento. Os correlatos cognitivos da aquisição da escrita na escola devem ser entendidos em relação às estruturas culturais e de poder que o contexto de aquisição de escrita na escola representa (KLEIMAN, 1995, p. 39).

Na perspectiva do modelo ideológico, o letramento não pode ser considerado como um conjunto de práticas individuais, mas como um conjunto de práticas sociais ligadas à leitura e à escrita desenvolvidas em um contexto social. Diante do exposto, nossa questão: qual concepção tem norteado as discussões teóricas sobre letramento no Brasil?, Marinho (2007) considera que: 
A concepção de letramento que vem ganhando hegemonia, no Brasil, é fruto de uma divergência entre os estudos interessados nas grandes conseqüências cognitivas, históricas e culturais atribuídas à escrita e aqueles interessados nas "práticas locais ou situadas" de letramento, uma corrente que se autodenomina Novos estudos sobre Letramento New Literacy Studies (NLS). Quando utilizamos os termos Modelo Autônomo, modelo ideológico, práticas de letramento, eventos de letramento, estamos aderindo a uma concepção de escrita, linguagem, de cultura, portanto, a uma concepção específica de letramento (MARINHO, 2007, p. 4, grifos do autor).

Os New Literacy Studies (NLS) tem como um dos mais influentes autores Brian Street. Para esse autor:

Pesquisas em NLS desafiam esta opinião e sugere que, na prática, a alfabetização varia de um contexto para outro e de uma cultura para outra e assim, portanto, tornam os efeitos da alfabetização diferentes em diferentes condições. A abordagem autônoma é simplesmente impor concepções ocidentais de alfabetização para outras culturas ou dentro de um país os de uma classe ou grupo cultural para os outros (STREET, 1984, p. 77).

No texto What's 'new' in New Literacy Studies? Critical approaches to literacy in theory and practice, Street (1984) aponta que a novidade nos novos estudos sobre letramento é a busca por estabelecer diálogos entre a sociologia, a antropologia e a linguística sendo os representantes dessas áreas Bourdieu, Foucault e Bakhtin. Essas interseções favoreceriam as análises das práticas e eventos de letramento a partir de investigações etnográficas.

Autores como Kleiman (1995), Marinho (2007), Macedo (2004) apontam em seus estudos as definições de práticas e eventos de letramento. Para esses autores, as práticas de letramento fazem referência às formas culturais de se utilizar a linguagem escrita. Como estão ligadas ao cultural, essas práticas se transformam de acordo com o contexto e expressam como cada grupo social entende a leitura e a escrita. Nesse sentido, o letramento passa a ser visto como uma construção coletiva interrelacionada com outros sistemas simbólicos. Inseridos nas práticas 
de letramento estão os eventos de letramento, "situações em que a escrita constitui parte essencial para fazer sentido da situação" (HEATH, 1983 apud KLEIMAN,1995, p. 40). Uma aula ou/e contar uma história à noite para os filhos são considerados eventos de letramento, atividades de interação com algum tipo de texto.

Sendo o letramento uma prática social, as práticas de letramento não se restringem apenas à escola, apesar dessa ser considerada, em quase todas as sociedades modernas, a principal agência de letramento. (ROJO, 2000) A escola se torna, portanto, uma das manifestações dessas práticas. Outras instituições, como a família e a igreja, também são responsáveis por essas práticas. No que tange o letramento escolar, segundo Kleimam (1995a), as práticas de leitura e escrita escolares têm como base o modelo autônomo, que considera a escrita como um modelo descontextualizado e sua aprendizagem como modelo individual. No entanto, conforme aponta Street (1984), não se pode tratar de letramento autônomo e letramento ideológico como dois conceitos dicotômicos. Tais conceitos são fruto de visões ideológicas diferentes acerca da escrita e de suas funções na sociedade. Em situações reais de uso da escrita, o que as pesquisas etnográficas têm apontado é o que podemos nomear como uma tensão existente entre esses dois modelos.

A aproximação entre os conceitos de lúdico e letramento, não apenas em nossas discussões, mas especialmente na concretização de projetos e ações de extensão, colocaram-nos diante da possibilidade de caracterização de um programa de extensão.

\section{O Programa de extensão Letramento e ludicidade}

Segundo as diretrizes do Forproex (BRASIL, 2007), para organizarmos as ações que desenvolvemos em um programa é necessário que: $1^{\circ}$ ) todas as ações de extensão universitária sejam classificadas em áreas do conhecimento, tendo por base as definidas pelo CNPq;

$2^{\circ}$ ) todas as ações de extensão sejam classificadas segundo a "área temática". A "classificação por área" deve observar o objeto ou assunto que é enfocado na ação. Mesmo que não se encontre no conjunto das áreas 
uma correspondência absoluta com o objeto da ação, a mais aproximada, tematicamente, deverá ser a escolhida;

$3^{\circ}$ ) todas as ações de extensão sejam organizadas a partir de uma linha de extensão. Segundo Forproex (2007)), " a denominação Linha de Extensão" substituiu, a partir de 2006, a denominação anterior Linha Programática; tem especial importância para a nucleação das ações de extensão. As linhas de extensão não são, necessariamente, ligadas a uma área temática, em especial;

$4^{\circ}$ ) passemos à identificação de projetos que atuam em uma mesma linha de extensão. Para tanto, devemos passar pela descrição dos projetos, aproximação dos atores, setores e instituições - incluindo equipes, departamentos e unidades acadêmicas -, articulação e integração dos mesmos, sob a forma de reuniões ou seminários temáticos, estabelecimento de mecanismos de gestão.

O programa de extensão que propomos se desenvolve na confluência entre a área temática de educação, na extensão, e mesma área de pesquisa, a partir da linha de extensão "Alfabetização, leitura e escrita", com ações definidas no segundo volume da Coleção extensão universitária do Forproex (BRASIL, 2007). “Alfabetização e letramento de crianças, jovens e adultos; formação do leitor e do produtor de textos; incentivo à leitura; literatura; desenvolvimento de metodologias de ensino da leitura e da escrita e sua inclusão nos projetos político-pedagógicos das escolas" (p. 28).

Nossa proposta é a estruturação de um programa de extensão que busque a promoção da leitura como leitura de mundo, tendo como elementos fundantes a noção de letramento e ludicidade, entendendo programa de acordo com Forproex (BRASIL, 2007): "como um conjunto de projetos de caráter orgâncio-instituicional, com clareza de diretrizes e voltados a um objetivo comum" (p. 35).

De acordo com as diretrizes do Forproex (BRASIL, 2007), "todas as ações de extensão deverão ser classificadas por área, por linha de extensão e também por linhas programáticas, cuja função é a indução ao agrupamento de projetos tematicamente assemelhados em programas" (p. 35). As diretrizes estabelecem 50 linhas programáticas que são utilizadas pelas agências nacionais de fomento. De acordo com as 
ementas, nossas ações poderiam se reunir à linha 31 - Incentivo à leitura - formação de leitor. Assim, teríamos as seguintes orientações para as ações do Núcleo de Pesquisa Educação, Subjetividade e Sociedade:

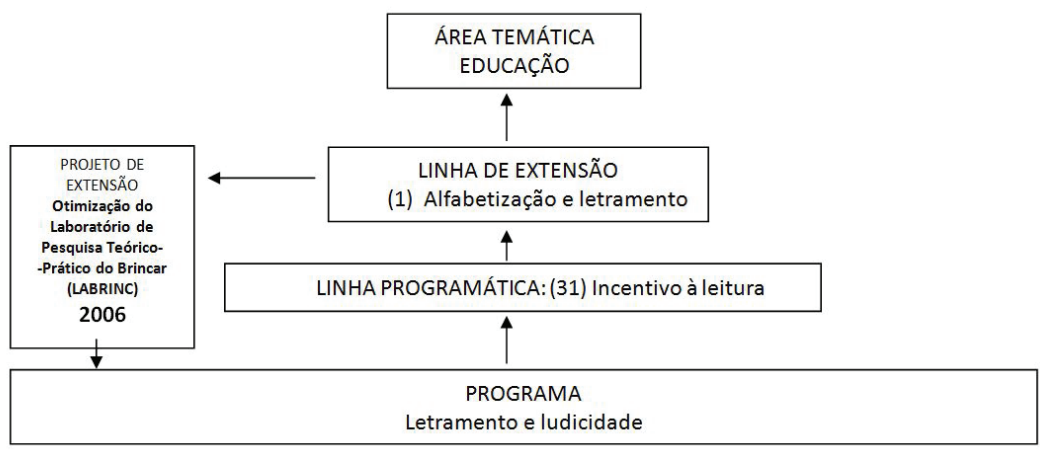

FIGURA 1 - Área e linhas do programa de extensão Letramento e ludicidade

Nossas ações estão organizadas a partir da grande área temática da educação, da linha de extensão (1) alfabetização e letramento, na linha programática (31) de incentivo à leitura, que se estrutura a partir das discussões e aproximações propostas pelo projeto de otimização do LABRINC dos conceitos de "letramento e ludicidade".

Atualmente, o Núcleo de Pesquisa Educação, Subjetividade e Sociedade é um grupo de pesquisadores que trabalha de forma transdisciplinar e interinstitucional organizado em duas linhas de pesquisa: "Discurso e conflito", que reúne pesquisadores interessados em estudos referentes às manifestações discursivas e sua natureza complexa, heterogenia e polifônica. É considera a ideia de que a linguagem constitui os sujeitos ao mesmo tempo em que constitutivamente se configura como a arena dos conflitos discursivos; e "Subjetividade e experiência", que integra pesquisadores que se interessam por estudos relativos às noções do "ter" e do "fazer" experiências para discussões sobre suas possíveis (ou impossíveis) interações no processo de constituição do sujeito, da subjetividade e da dessubjetividade.

O LABRINC, hoje, congrega uma equipe de oito pesquisadores sendo coordenado pelo NPESS. A transdisciplinaridade pode ser sentida na 
formação básica de cada membro: Mauro Rocha Baptista é Doutor em Ciência da Religião/Filosofia da Religião e atualmente lidera o NPESS a partir do qual coordena o projeto de pesquisa O lúdico e a educação, com financiamento da FAPEMIG; Elisabeth Gonçalves de Souza é doutoranda em linguística, tendo se mestrado na área de educação, e atualmente coordena o LABRINC; Janaína de Assis Rufino é doutora em estudos linguísticos; Cláudio José Guilarduci é professor da UFSJ e Pós-Doutor em artes cênicas, graduado em filosofia; Felipe Bastos Mansur da Silva é doutor em teoria literária e professor da rede particular do ensino médio do Rio de Janeiro; Helder Rodrigues Pereira é professor da UNIPAC, Doutor em estudos linguísticos e graduado em filosofia; Josemir Medeiros da Silva é mestre em educação e graduado em jornalismo; e Rafael Soares de Oliveira é tutor do curso de aperfeiçoamento a distância da UFSJ, mestre em estudos culturais e da memória e graduado em filosofia. O grupo se completa ainda com dez especialistas das áreas de educação, computação, matemática, história, psicologia e filosofia, além de quatorze bolsistas e outros dez alunos voluntários. É na diversidade da equipe formada, que agrega desde estudantes do ensino médio até doutores, que o LABRINC encontra força para contribuir com o avanço e a consolidação do conhecimento científico, não só especificamente na área educacional, como no ambiente das humanidades como um todo.

\section{As ações do programa Letramento e ludicidade}

Para estruturar as ações extensionistas desenvolvidas pelo Núcleo de Pesquisa, começamos pelos projetos, tomados a partir da definição sugerida pelo Forproex (BRASIL, 2007, p. 35): “conjunto de ações processuais contínuas, de caráter educativo, social, cultural, científico e tecnológico com objetivo específico e prazo determinado":

(I) Projeto de extensão Nós e artes: uma proposta de leitura e produção de textos através dos grandes mestres da pintura.

Projeto pensado a partir de demandas da comunidade com objetivo de construir de forma progressiva o conhecimento sobre leitura e escrita, buscando comportamentos críticos por parte dos alunos. Natureza: 
Extensão. Coordenadora: Janaína de Assis Rufino. Integrantes: Elisabeth Gonçalves de Souza, Maria de Fátima Teixeira Gomes, Elaine Leporate Barroso Faria, Maria das Graças Assun e Renata Gláucia dos Santos (aluna-bolsista). Financiador: Realizado desde 2008, a princípio sem fomento, porém, a partir de 2010, com fomento do Programa de Apoio a Extensão da UEMG.

(II) Projeto de extensão Jornal: modos de fazer, modos de usar I e II Projeto realizado com o objetivo de aproximar a comunicação social das práticas docentes, de ecnol com a visão da educomunicação alcançando ainda a capacitação dos graduandos do curso de pedagogia da UEMG-Barbacena para o uso das práticas de educomunicação através da mídia impressa e eletrônica e da ecnologia da comunicação na sua prática docente. Natureza: Extensão. Coordenadora: Elisabeth Gonçalves de Souza. Integrantes: Josemir Medeiros, Janaína de Assis Rufino e Maria de Fátima Teixeira Gomes. Financiador: Programa institucional de Apoio a Extensão da UEMG. (III) Projeto transdisciplinar de ensino-pesquisa-extensão arte, loucura e educação: por uma crítica da loucura prática

Projeto realizado com o objetivo de possibilitar através da integração transdisciplinar da estrutura ensino-pesquisa-extensão que os discentes tomem contato com a identidade regional ligada à temática da loucura e as possibilidades criativas que essa ligação gera. Natureza: Extensão. Coordenadores: Mauro Rocha Baptista, Janaína de Assis Rufino, Maria de Fátima Teixeira Gomes e Andrea Cristina de Oliveira Antão. Integrantes: membros do núcleo. Financiador: sem fomento.

(IV) Quem conta um conto, aumenta um ponto: a contação de histórias e o lúdico Projeto realizado com os seguintes objetivos: contribuir para o desenvolvimento habilidades de leitura e escrita a partir das oficinas que, além da contação de histórias, propiciarão momentos de registro escrito e de discussões; desenvolver o imaginário infantill, em situações de interação visando contribuir para a formação de acadêmicos em pedagogia da UEMG-Barbacena e ainda estreitar os laços entre universidade e comunidade. Natureza: Extensão. Coordenador: Elisabeth Gonçalves de Souza e Andrea Cristina de Oliveira Antão. Integrantes: Todos os membros do Núcleo. Financiador: Sem fomento. 
(V) Humanismo e educação

Partindo da noção de que a relação entre a sociedade e subjetividade se dá no conflito, apresentamos como proposta de discussão uma releitura do humanismo que valorize a função do debate como o único centro de argumentação em que a educação pode, de fato, cumprir o seu papel de formadora. Observamos que, como instrumento institucionalizado, a educação tende a refletir os interesses coercitivos da sociedade; nesse caso, enquanto, pretensamente, ela forma sujeitos, efetivamente, ela deforma subjetividades. Tomados por essa inquietação com o paradoxo do humanismo clássico é que propomos esta discussão sobre um outro humanismo. Fundamentamos essa discussão no escritor tcheco Franz Kafka e no filósofo francês Jean-Paul Sartre, que ao descreverem o absurdo da sociedade abrem espaço para um novo olhar sobre o homem. Nesse novo humanismo, não se requer a superioridade do homem sobre qualquer coisa que seja, mas se pretende centrar na pequenez do homem, o objeto de nossa atenção. Ciente de sua condição de inferioridade diante do mundo e da sociedade, a subjetividade pode encontrar forças para viver plenamente a sua angústia, e, só então, alcançar o estatuto de agente, deixando de ser mera ouvinte do discurso social. Esta subjetividade ativa - promovida pelo humanismo, conforme esse foi revisitado pelo existencialismo - possibilita que a educação encontre a sua verdadeira natureza, permitindo que a partir de então o debate seja o motor único e a argumentação o único método capaz de desenvolver e formar uma sociedade consciente, na qual a alienação seja substituída pelo convencimento racional, a harmonia pelo salutar combate de ideias e, enfim, a quantidade pela qualidade. Módulo I/2009 - Bolsa PAEx/UEMG/ESTADO para o desenvolvimento do curso: Debate e argumentação: por uma educação humanista, fundamentado no debate das obras de Kafka e destinado a alunos do ensino médio. Módulo II/ 2010 - círculo literário. Natureza: Extensão com desdobramentos na pesquisa. Coordenador: Mauro Rocha Baptista. Integrantes: Rosilena Aparecida Damasceno, Lucimara Aparecida Gomes, Alexia Cristina Portes Araújo, Petrônio de Paula Batista Filho, Renata Viol Ferreira da Silva, Bianca Cristina Chagas, Arabela Maperso Moreira, Lílian Veiga de Carvalho, Carolina Santarosa Pereira, Alíona Aparecida Damasceno de Oliveira, 
Vanderlei Procópio, Financiador: Universidade do Estado de Minas Gerais.

O programa estruturado, a partir de seus projetos, oferece outras ações de extensão relacionadas à linha de extensão à qual atende o programa, como cursos, eventos, prestação de serviços e elaboração e publicação/difusão de produtos acadêmicos. Muitas dessas ações - desenvolvidas em parceria pelos projetos e seus participantes - têm forte ação consolidadora do programa.

A descrição de nossas ações continua pelos cursos e eventos. Denominamos curso e evento também a partir do Forproex (BRASIL, 2007, p. 36-38). O primeiro, consideramos com "um conjunto articulado de ações pedagógicas, de caráter teórico prático, presencial ou a distância, planejadas e organizadas de maneira sistemática, com carga horária definida e processo de avaliação formal". Já o segundo, para nós, é uma "ação que implica na apresentação e/ou exibição pública, livre ou com clientela específica, do conhecimento ou produto cultural, artístico, esportivo, científico e tecnológico desenvolvido, conservado ou reconhecido pela Universidade".

1) Curso de aperfeiçoamento profissional ${ }^{* 4}$ : A construção do espaço sujeitoprofessor nas práticas de leitura (2007). Responsável: Maria de Fátima Teixeira Gomes.

2) Curso de aperfeiçoamento profissional*: A construção do espaço sujeito-professor nas práticas produção de texto: uso dos conectores (2008). Responsável: Maria de Fátima Teixeira Gomes.

3) Curso de aperfeiçoamento profissional*: A biblioteca e a leitura literária nas escolas públicas de Barbacena (2009). Responsáveis: Maria de Fátima Teixeira Gomes e Janaína de Assis Rufino.

4) Curso de aperfeiçoamento profissional*: Teatro cômico popular e educação (2009). Responsável: Cláudio Guilladuci.

5) Curso de aperfeiçoamento profissional*: Transpondo o fracasso escolar na construção da subjetividade a partir das práticas de leitura do gênero canção (2008). Responsável: Elaine Leporate.

6) Curso de aperfeiçoamento profissional: Os Saltimbancos na educação infantil: canções numa perspectiva discursiva (2009). Responsáveis: Janaína

6 Os cursos marcados com um asterisco $\left(^{*}\right)$ foram organizados em forma projetos de extensão financiados por agências de fomento. 
de Assis Rufino e alunas de orientação.

7) Curso de aperfeiçoamento profissional: Processos de letramento no ensino-aprendizagem da leitura e da escrita na educação básica (2011). Responsáveis: Janaína de Assis Rufino, Andréa Cristina Antão, Maria de Fátima Teixeira Gomes e Elisabeth Gonçalves de Souza.

8) Curso de aperfeiçoamento profissional: Diferentes formas de ensinar matemática (2011). Responsáveis: Janaína de Assis Rufino, Andréa Cristina Antão, Maria de Fátima Teixeira Gomes e Elisabeth Gonçalves de Souza.

Ainda contamos com dois cursos que estão diretamente relacionados a projetos um ao projeto Nós e arte: uma proposta de leitura e produção de textos através dos grandes mestres da pintura e outro ao projeto Humanismo e educação:

1) Curso de aperfeiçoamento profissional: Nós e artes: repensando a formação do professor (2009). Responsáveis: Janaína de Assis Rufino, Renata Gláucia dos Santos e alunas da linha de pesquisa Discurso e conflito. 2) Curso de aperfeiçoamento profissional*: Ludicidade como resgate do humanismo na educação (2010/2011). Responsáveis: Mauro Rocha Baptista, Wellinghton Elias de Jesus e alunos de orientação.

Quanto aos eventos podemos dividir as ações em:

a) Relacionadas aos projetos:

1) Círculo literário - 2010/2011

2) Contação de histórias em escolas públicas municipais - 2011

3) UEMG vai ao cinema - 2011

4) Sessão de filme: O bicho de sete cabeças - 12/08/11

5) Mesa-redonda: Literatura e loucura - 20/08/11

6) Visitas técnicas ao Museu da Loucura - 09/11

7) Mesa-redonda: Olhares sobre a loucura - 27/09/11

8) Exposição de fotos - 10/11

9) Exposição de portifólios - 11/11

b) Relacionadas diretamente ao programa:

1) $1^{\circ}$ Colóquio de Pesquisa da UEMG Barbacena: Educação, subjetividade 
e sociedade -2008

2) $1^{\circ}$ Encontro Externo do Núcleo de Pesquisa Educação: Subjetividade e Sociedade - 2011

3) Lançamentos dos números da revista Mal-Estar e sociedade - 2009, 2010

4) Atividades do LABRINC 5 .

Para finalizar, é importante a descrição das atividades de publicação que desenvolvemos no que estamos chamando e estruturando como nosso programa de extensão. Em 2008, os membros do núcleo propõem à FAPEMIG, sob a coordenação do professor Fuad Kyrilos Neto, um projeto, cujo objetivo foi a produção de um periódico. É importante salientar que o financiamento desse projeto foi de extrema importância para a consolidação da Editora da UEMG, a EdUEMG. Dessa forma, desde 2008, o Núcleo de Pesquisa Educação, Subjetividade e Sociedade é responsável pela organização da revista Mal-Estar e sociedade. Além do periódico em 2009, esse grupo de profesores, sob a organização de Janaína de Assis Rufino, Mauro Rocha Baptista e Fuad Kyrillos Neto, lança o livro Espaços, sujeitos e sociedade: diálogos, com o objetivo de divulgar as principais discussões estabelecidas pelo núcleo até então. Paralelamente ao periódico e ao livro, os membros do Núcleo de Pesquisa Educação, Subjetividade e Sociedade vêm apresentando diversas produções em conjunto das quais citamos, por exemplo:

1) BAPTISTA, Mauro Rocha; RUFINO, Janaína de Assis; SOUZA, Elisabeth Gonçalves de. Letramento e ludicidade: teoria e prática nas ações do Laboratório Teórico-Prático do Brincar - LABRINC. In: SEMINÁRIO INTERNACIONAL, 6., 2011, Rio de Janeiro. Anais... Rio de Janeiro: UERJ, 2011, p. 1-13.

2) GOMES, Maria de Fátima Teixeira; RUFINO, Janaína de Assis. Cortinas descerradas, a realidade em cena: análise enunciativa e polifônica da

7 Atividades com crianças no LABRINC, essas atividades estão acontecendo de forma esporádica desde a criação do laboratório e foram oficializadas para acontecer regularmente a partir do segundo semestre de 2010. São atividades envolvendo os alunos participantes do NPESS e alunos da rede pública local. Nessas atividades, sob a supervisão de um dos pesquisadores do NPESS, os alunos desenvolvem os conceitos sobre o lúdico trabalhados na teoria de forma prática. Os alunos envolvidos podem sentir na prática o que trabalham na teoria e refrescar a teoria com suas noções de prática. Os professores que supervisionam as atividades podem testar a aplicabilidade das indicações que são feitas a seus alunos. E a forma com que as crianças desenvolvem é o melhor dos resultados. Tornam-se mais abertas para a discussão e mais provocativas a novas discussões, não aceitando uma resposta vazia, nem o argumento de autoridade, fazendo valer de fato seu letramento para viver na democracia moderna. 
apresentação do livro "Nos porões da loucura". In: KYRILLOS NETO, Fuad; RUFINO, Janaína de Assis; BAPTISTA, Mauro Rocha. (org.). Espaços, sujeitos e sociedade: diálogos. Barbacena: EdUEMG, 2009, p. 43-54. 3) KYRILLOS NETO, Fuad; RUFINO, Janaína de Assis; BAPTISTA, Mauro Rocha. Liminar. In: KYRILLOS NETO, Fuad; RUFINO, Janaína de Assis; BAPTISTA, Mauro Rocha. (Org.). Espaços, sujeitos e sociedade: diálogos. Barbacena: EdUEMG, 2009, p. 9-14.

4) RUFINO, Janaína de Assis; SOUZA, Elisabeth Gonçalves de. A Polifonia e o Discurso Docente: estratégias para compreender o processo de escolha do Livro Didático. In: SIMPÓSIOSOBRE O LIVRO DIDÁTICO DE LÍNGUA MATERNA E ESTRANGEIRA, 1., 2008, Rio de Janeiro. Anais... Rio de Janeiro: PUC-Rio, 2007, [s.p.].

\section{Considerações finais}

Acreditamos termos sido capazes de propor um programa consistente de extensão a partir das ações que vimos desenvolvendo sob a orientação das considerações teóricas das pesquisas do Núcleo de Pesquisa Educação, Subjetividade e Sociedade. Ao apresentarmos nosso programa de extensão - Letramento e ludicidade -, é preciso ter muito claro que não só pretendemos nos adequar ao que propõem os documentos oficiais das universidades públicas no que se referem às atividades extensionistas, mas também buscamos uma forma de agir, da comunidade acadêmica pautada no papel principal que a universidade deve assumir na sociedade. Acreditamos ser absolutamente necessário ter consciência de que o compromisso da universidade com a sociedade não pode se dar de forma autônoma e voluntarista, mas que deve estar articulado a um movimento de gestão, por meio de políticas e diretrizes institucionais que possibilitem criar condições para a promoção de uma dinâmica de atuação e compreensão, as quais são forças, em nosso ponto de vista, mobilizadoras para a transformação da prática pedagógica docente, da atividade discente e da própria comunidade em que a universidade se encontra inserida.

O grande desafio da extensão universitária é a sua consolidação como resposta aos desafios colocados às universidades públicas brasileiras, tanto 
por aqueles que querem flexibilidade, competição e eficiência, quanto por aqueles que exigem um caráter mais popular. Em outras palavras, podemos dizer que isso significa que a formação universitária deve ser efetivada com amplitude para que se transforme num horizonte mais amplo de estudo e produção e socialização de conhecimentos, e isso somente será possível com a indissociabilidade do ensino, da pesquisa e da extensão.

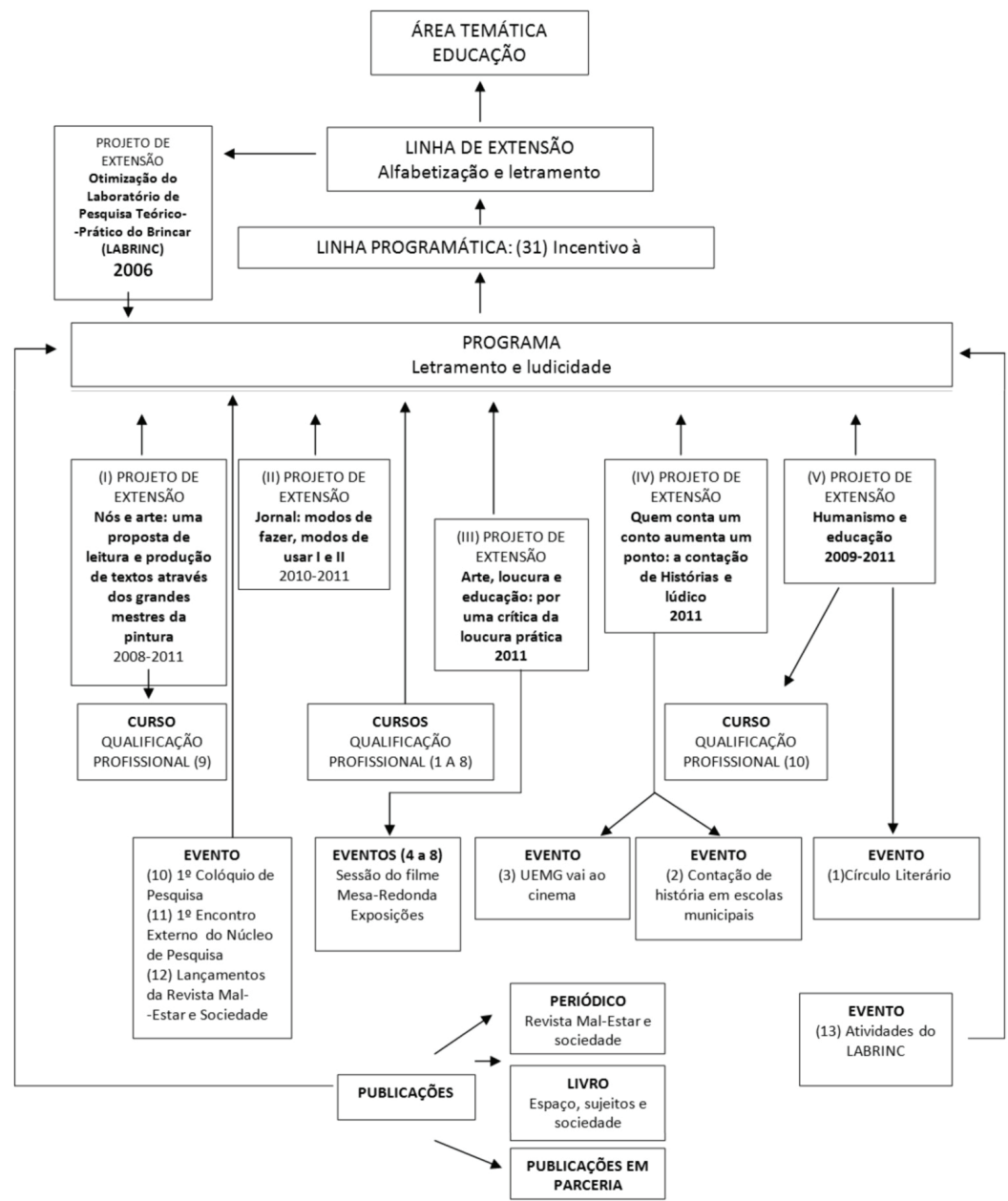

FIGURA 2 - Organograma do programa de extensão Letramento e ludicidade 


\section{Referências}

AGAMBEN, Giorgio. Estâncias: a palavra e o fantasma na cultura ocidental. Belo Horizonte, UFMG, 2008.

BRASIL. Ministério da Educacão. Plano Nacional de Extensão Universitária Edição Atualizada Brasil 1997/2007. Fórum de Pró-Reitores de Extensão das Universidades Publicas Brasileiras e SESU/MEC. 2007.

FREIRE, Paulo. Educação e mudança. Rio de Janeiro: Paz e terra, 1980.

GADAMER, H. G. Verdade e método. Petrópolis: Vozes, 1997

KLEIMAN, Angela. Modelos de letramento e as práticas de alfabetização na escola. In: KLEIMAN, Angela (org.). Os significados do letramento. Campinas: Mercado das Letras, 1995a. p. 15-61.

LIMA, Ariadne. Laboratório multidisciplinar da UEMG é espaço para pesquisas e refelexao sobre as infuências do lúdico na vida humana. Minas Faz Ciência, fascículo 35, p. 46-47, set./nov. 2008.

MACEDO, Maria do Socorro. Interações e práticas de letramento em sala de aula: o uso do livro didático e da metodologia de projetos. Tese (Doutorado em Educação) - Faculdade de Educação, Universidade Federal de Minas Gerais, Belo Horizonte, 2004.

MARINHO, Marildes. Que novidades trouxeram os novos estudos sobre letramento. In: ENCONTRO DE PESQUISA EM EDUCAÇÃO DA REGIÃO SUDESTE, 8., 2007, Vitória. Anais... Vitória de 27 a 30 de maio 2007.

ROJO, Roxane. Letramento escolar: construção de saberes ou maneiras de impor o saber? In: CONFERENCE FOR SÓCIO-CULTURAL 
RESEARCH. SIMPÓSIO CULTURA DA ESCRITA E PRÁTICAS ESCOLARES DE LETRAMENTO, 3., 2000, Campinas. Cadernos de resumos. Campinas: ISSC/UNICAMP, 2000.

SCRIBNER, Sylvia; COLE, Michael. The psychology of literrace. Massachussets: Haravard University Press, 1981.

SOARES, Magda. Letramento: um tema em três gêneros. Belo Horizonte: Autêntica, 2004.

STREET, Brian. Literacy in theory and practice. New York: Cambridge University Press, 1984.

KYRILLOS NETO, Fuad; RUFINO, Janaína de Assis; BAPTISTA, Mauro Rocha. Liminar. In: KYRILLOS NETO, Fuad; RUFINO, Janaína de Assis; BAPTISTA, Mauro Rocha. (Org.). Espaços, sujeitos e sociedade: diálogos. Barbacena: EdUEMG, 2009

TFOUNI, Leda Verdiane. Adultos não alfabetizados: o avesso do avesso. Campinas: Pontes, 1988. 


\title{
Literacy and leisure: the organization of an extension program
}

\begin{abstract}
This article aims to discuss theoretical and practical perspectives that move the Laboratory of Theoretical and Practical Play (Laboratório TeóricoPrático do Brincar - LABRINC), seeking a reflection that allows us to achieve a systematization of our actions and allow us to propose an extension of these actions nucleation, ie, that allows us to reflect on the construction of an extension program for the actions developed in the Center for Research Education, Subjectivity and Society. We believe that the systematization of the actions of extension programs is a very effective mechanism for universities to meet the guidelines of impact, social interaction, dialogue, partnership building, and integrating interdisciplinary teaching / research / extension, as expected also on decisions taken FORPROEX (BRAZIL, 2007).
\end{abstract}

Keywords: Extension program, literacy, playfulness.

Recebido: 13/07/2012

Aprovado: 28/11/2012 